\title{
El Tribunal de Justicia de la Comunidad Andina y la singularidad del proceso de integración andino
}

\author{
Yolanda Mendoza Neyra*
}

\section{Resumen}

Los órganos e instituciones del Sistema Andino de Integración son los que realmente diseñan, orientan, regulan y aseguran la consolidación de la Comunidad Andina. De allí surge nuestro interés por analizar uno de ellos cuya existencia es indispensable para la supranacionalidad del proceso de integración andino; nos referimos a su Tribunal de Justicia. En este artículo sostenemos que su actividad jurisdiccional y el ordenamiento andino marcan el distanciamiento del proceso de integración europeo, y proporcionan identidad y singularidad a la integración andina, haciéndola única entre ambos procesos.

Palabras claves: Comunidad Andina, integración regional, Tribunal de Justicia de la Comunidad Andina, Tribunal de Justicia de la Unión Europea, Unión Europea.

\section{The Andean Court of Justice and the uniqueness of the Andean integration process}

\section{Abstract}

The bodies and institutions of the Andean Integration System are the ones that really design, guide, regulate and ensure the consolidation of the Andean Community. From there arises our interest in analyzing one of them, whose existence is essential for the supranationality of the Andean integration process. We refer to the Andean Court of Justice. In this article we argue that both its judicial activity and the Andean legal system mark the distance from the European integration process, and thus provide identity and singularity to the Andean integration, making it unique when comparing both processes.

Keywords: Andean Community, regional integration, Andean Court of Justice, Court of Justice of the European Union, European Union.

* Abogada de la Universidad de Lima, Especialidad en Derecho Internacional Público por la Pontificia Universidad Católica del Perú. ‘a20183609@pucp.edu.pe`.

Recibido: 19 de diciemre de 2019 | Revisado: 14 julio de 2020 | Aceptado: 4 de agosto de 2020 .

Para citar este artículo: Mendoza Neyra, Yolanda. "El Tribunal de Justicia de la Comunidad Andina y la singularidad del proceso de integración andino". Comentario Internacional 20 (2020): 201-219. doi: $10.32719 / 26312549.2020 .20 .1 .1$ 


\section{Introducción}

De los cincuenta años de vida institucional de la Comunidad Andina (CAN), indiscutiblemente cuarenta de ellos se debe a la acertada decisión política de sus países miembros por crear un Tribunal de Justicia. Gracias a su existencia, desde 1984 nuestro proceso de integración (en adelante, proceso andino) dejó el esquema de la cooperación internacional para transformarse en uno supranacional, ${ }^{1}$ muy similar al que venía desarrollándose en la Europa occidental. Por lo general, ambos procesos de integración son objetos de estudios y comparaciones, cuyos resultados giran en torno a los beneficios que ofrece el modelo europeo y cómo los mismos son absorbidos por su contraparte andina. Tales expresiones también son utilizadas para respaldar otros análisis académicos que consideran a los órganos comunitarios de la CAN como una réplica o copia de las instituciones del proceso de la Unión Europea ${ }^{2}$ (en adelante, proceso europeo), sin reparar que estos sirvieron de inspiración.

Creemos que el Tribunal de Justicia de la Comunidad Andina (TJCA) es el órgano comunitario que brinda los mejores elementos para marcar el distanciamiento de la estructura institucional de la Unión Europea (UE), a pesar que sobre él recaiga severos cuestionamientos por su falta de ambición ${ }^{3}$ y originalidad en las fundamentaciones de sus sentencias. Por esta razón, expondremos las diferencias más determinantes entre el TJCA y el Tribunal de Justicia de la Unión Europea (TJUE), los más significativos eventos de la vida institucional y actividades jurisdiccionales de nuestro Tribunal, y normas específicas del ordenamiento jurídico andino (en adelante, ordenamiento andino), que en conjunto justifican la singularidad del proceso andino.

1. Michel Levi, "La Unión Europea y la Comunidad Andina: relaciones entre los procesos de integración", en Europa y América Latina. El otro diálogo transatlántico, ed. José María Beneyto y Patricia Argerey (Madrid, ES: Instituto Universitario de Estudios Europeos, 2006), 116-18.

2. Karen J. Alter y Laurence R. Helfer, Transplanting International Courts - The Law and Politics of the Andean Tribunal of Justice (Oxford, UK: Oxford University Express, 2017), 36.

3. William Phelan, "Enforcement and Escape in the Andean Community: Why the Andean Community of Nations is Not a Replica of the European Union", Journal of Common Market Studies 53, n. ${ }^{\circ}$ (2015): 844. 


\section{Sobre el origen y la evolución del Tribunal de Justicia de la Comunidad Andina}

Para empezar a explicar cómo el TJCA ha forjado la singularidad de nuestro proceso, sin que pierda la supranacionalidad, debemos de revisar: bajo qué circunstancias se suscribió el Acuerdo de Integración Subregional y el Tratado que crea el TJCA; y cuáles han sido las más importantes coyunturas internacionales y decisiones políticas de los países miembros que afectaron -positiva o negativamente- el funcionamiento y la evolución de la CAN y de su órgano jurisdiccional. A fin de lograr una mejor comprensión de este trayecto, optamos por dividirlo en tres etapas que desarrollamos a continuación.

Desde los primeros proyectos de integración regional hasta la entrada en vigor del Tratado de Creación del Tribunal de Justicia del Acuerdo de Cartagena

Como sabemos, el reiterado compromiso de los Estados de América Latina y el Caribe de convertir a esta región en uno de los mercados más importantes del mundo, es una meta integracionista que data desde principios de 1950. Con el objetivo de conseguir una unión regional, en esta época estos Estados decidieron imitar el proceso europeo sin tener presente sus propias realidades económicas y políticas. Para respaldar dicha decisión utilizaron parcialmente las recomendaciones proteccionistas de la Comisión Económica para América Latina y El Caribe (CEPAL) ${ }^{4}$ sobre el desarrollo económico y equilibrado que debían aplicarse si se deseaba establecer un Mercado Común Latinoamericano. De este modo, y sin una amplia experiencia en cooperación internacional e integración económica, ${ }^{5}$ durante el primer quinquenio de la década de 1960 surgieron distintos proyectos regionales. Así tenemos a la Asociación Latinoamericana de Libre Comercio

4. Se sugirió la industrialización en forma progresiva de los países de la región a fin de eliminar la dependencia de las importaciones y la unión de los mercados, esperando que generase una mayor productividad. Raúl Prebisch, "El desarrollo económico de la América Latina y algunos de sus principales problemas", en Cincuenta años del pensamiento de la CEPAL: textos seleccionados, ed. CEPAL (Santiago, CH: Fondo de Cultura Económica, 1998), 66 y 115.

5. Edwin P. Lochridge, "The Role of the Andean Court in Consolidating Regional Integration Efforts", Georgia Journal of International and Comparative Law 10, n. 2 (1980): 356. 
(1960), al Mercado Común Centroamericano (1960) y a la Asociación de Libre Comercio del Caribe (1965).

Ya que dentro de ellos se volvía imposible conseguir la total satisfacción integracionista de sus miembros, y frente a la carencia de la voluntad política para cumplir con los plazos pactados, ${ }^{6}$ los Estados que se consideraban más próximos -o compartían las mismas aspiraciones- se reagruparon con el fin de encontrar soluciones más acordes con sus realidades. Una clara prueba de ello fue lo sucedido en la Asociación Latinoamericana de Libre Comercio (ALALC); cinco de sus Estados partes con distintos grados de desarrollo económico, eligieron mejorar sus progresos y aceleramientos bajo un nuevo acuerdo subregional. ${ }^{?}$

Así pues, en 1969 esta reconfiguración de la integración latinoamericana y caribeña quedó establecida tras la ratificación del Acuerdo de Integración Subregional (o Acuerdo de Cartagena, en adelante el Acuerdo), permitiendo el nacimiento del Pacto Andino o Grupo Andino con el principal objetivo de establecer una unión aduanera para fines de $1980 .{ }^{8}$ Cabe resaltar que, entre las finalidades de este proyecto subregional se consignó una que, en nuestra opinión, fue la más importante para la integración regional: "establecer condiciones favorables para la conversión de la ALALC en un mercado común".

Pese al ambiente optimista por alcanzar, esta vez, todas las metas económicas y comerciales, dicha renovación integracionista poseía un alarmante defecto. Una de las grandes omisiones o -mejor dicho- de los serios obstáculos que el mismo Acuerdo fomentaba era la carencia de un propio órgano o institución jurisdiccional, ${ }^{10}$ que de existir debía encargarse de ga-

6. En el caso de la Asociación Latinoamericana de Libre Comercio (ALALC), su propósito era crear un área de libre comercio en toda la región antes del 31 de diciembre de 1972. En 1980, fue sustituida por la Asociación Latinoamericana de Integración (ALADI).

En cuanto al Mercado Común Centroamericano, se planteó su establecimiento dentro de los cinco años posteriores a la entrada en vigor de su tratado constitutivo (1966). En 1991, se institucionalizó como Sistema de Integración Centroamericano (SICA).

En la Asociación de Libre Comercio del Caribe se pactó establecer una comunidad económica de libre comercio para 1968. En 1973. fue reemplazada por la Comunidad del Caribe (CARICOM).

7. La Declaración de los Presidentes de América de 1967 señaló que este tipo de acuerdo era transitorio.

8. Comunidad Andina, Acuerdo de Cartagena, 26 de mayo de 1969, Art. 1

9. Ibid., Art. 61.

10. En el Artículo 23 de la versión original del Acuerdo se señaló que la Comisión era la encargada de llevar los procedimientos de negociación, buenos oficios, mediación y conciliación. En caso de no llegar a un 
rantizar la aplicación del ordenamiento andino y el cumplimiento de sus disposiciones originarias y derivadas.

De hecho, existen diversas explicaciones sobre esta grave omisión: algunos piensan que fue causado por los creadores del Acuerdo, porque la mayoría de ellos al ser especialistas económicos y comerciales ${ }^{11}$ no tuvieron la debida diligencia en la redacción de las reglas de solución de controversias; y otros creen que frente a un "mecanismo relativamente simple de liberación comercial no era necesario una estructura institucional poderosa". ${ }^{12}$ Para salir de esta problemática y del incumplimiento sistemático de los países miembros del Pacto Andino que inestabilizaba el Acuerdo y estancaba su proceso, ${ }^{13}$ en 1979 se suscribió el Tratado que crea el Tribunal de Justicia del Acuerdo de Cartagena (en adelante, el Tratado).

Recordemos que por esa época los países miembros eran extremadamente cautelosos en cuanto a su soberanía, ${ }^{14}$ por lo que era de esperarse que sus gobiernos prefirieran las resoluciones de sus cortes nacionales. Pese a ello, y considerando las opiniones de los expertos del Instituto para la Integración de América Latina y El Caribe (INTAL) ${ }^{15}$-y así distanciarse de la ALALC-, durante el diseño del proyecto del Tratado quedó la idea fija de un órgano jurisdiccional muy similar al Tribunal de Justicia de las Comunidades Europeas (hoy TJUE),${ }^{16}$ pero enfocado a la propia realidad e intereses de la subregión. Lo último, también significó que el ordenamiento andino pasaría a estar regido por los mismos principios de un Derecho sui generis (es decir, el Derecho Comunitario) que regulaba y era esencial para la integración europea: primacía, aplicabilidad directa y efecto directo.

consenso, los países miembros debían remitirse a las disposiciones del Protocolo para la Solución de Controversias de la ALALC.

11. Lochridge, "The Role of the Andean Court in Consolidating Regional Integration Efforts", 352.

12. Francisco Orrego Vicuña, "La creación de un tribunal de justicia en el Grupo Andino", Revista Derecho de la Integración, n. ${ }^{\circ} 15$ (1974): 31.

13. Además del retiro de Chile en 1976, el resto de países miembros no manifestaban interés para impulsar la creación del Arancel Externo Mínimo Común y de los Programas Sectoriales de Desarrollo Industrial.

14. Osvaldo Saldías, "Networks, Courts and Regional Integration Explaining the Establishment of the Andean Court of Justice", KFG Working Paper Series, n. 20 (2010): 8.

15. Ver el Estudio sobre Procedimientos para Solucionar Conflictos del INTAL de 1972.

16. Luis Carlos Sáchica, "El Ordenamiento Jurídico Andino y su Tribunal de Justicia”, en El Tribunal de Justicia del Acuerdo de Cartagena, ed. Instituto para la Integración de América Latina (Buenos Aires, ARG: INTAL 1985), 13. 
Tras la ratificación del Tratado, ${ }^{17}$ en 1983, se materializó la urgencia de crear un sistema de solución de controversias que moderara las discusiones políticas de los países miembros. ${ }^{18}$ De este modo, el Tribunal de Justicia del Acuerdo de Cartagena (en adelante, el Tribunal) se convirtió en el órgano jurisdiccional del Pacto Andino con "capacidad de declarar el derecho comunitario, dirimir las controversias que surjan del mismo e interpretarlo uniformemente". ${ }^{19}$ Con respecto a sus competencias, las primeras de ellas estuvieron relacionadas con el control de la legalidad -acción de nulidad y acción de incumplimiento- y la aplicación uniforme -interpretación por vía prejudicial- del ordenamiento andino. Desde entonces, el Tribunal pasó a ser visto como un clon jurisdiccional ${ }^{20}$ del TJUE.

\section{Desde el establecimiento del Tribunal Andino hasta la firma del Protocolo Modificatorio del Tratado de Creación del Tribunal de Justicia del Acuerdo de Cartagena}

A menos de un año de su instalación -es decir hacia 1984-, los países miembros comenzaron a restarle importancia. A nuestro parecer, no comprendían que debido a la existencia del Tribunal -además de perfeccionar el proceso andino- lo convertía en el único proceso de integración supranacional en América Latina y El Caribe. Por este motivo, opinamos que esta reprochable e irresponsable conducta no solo impidió el normal desenvolvimiento del Tribunal; sino también por un breve tiempo ocasionó su infravaloración. Sustentamos lo explicado hasta aquí con los siguientes hechos: la decisión de los países miembros para no iniciar proceso alguno ante este órgano ${ }^{21}$ y la búsqueda de un sistema jurisdiccional que les fuese más "informal y flexible".22

17. Su Artículo 37 dispuso que el Tratado entraría en vigencia cuando todos los países miembros que lo suscriben hayan depositado el respectivo instrumento de ratificación en la Secretaría de la Comisión del Acuerdo de Cartagena. Venezuela fue el último que depositó su ratificación el 19 de mayo de 1983.

18. Jorge Antonio Quindimil López, Instituciones y Derecho de la Comunidad (Valencia, ES: Tirant lo Blanch, 2006), 330.

19. Comunidad Andina, Tratado de creación del Tribunal De Justicia De La Comunidad Andina, 28 de mayo de 1979, párrafo final del Preámbulo.

20. Karen Alter y Laurence R. Helfer, "The Andean Tribunal of Justice and its interlocutors: Understanding preliminary reference patterns in the Andean Community", Journal of International Law and Politics, n. 41 (2009): 874 .

21. Quindimil López, Instituciones y Derecho de la Comunidad, 341.

22. Ver Acta de Caracas de 1991 - V Reunión del Consejo Presidencial Andino. Sobre los Aspectos Institucionales, se acordó "[...] Establecer un mecanismo informal y flexible para la solución de controversias entre los países miembros con respecto a los incumplimientos que afectan el comercio intrasubregional". 
Como era de esperarse, durante la primera década de funcionamiento del Tribunal (1984-1994) solo se recibieron: ${ }^{23} 41$ solicitudes de interpretación prejudicial, 4 acciones de nulidad -todas iniciadas por Colombia-, y ninguna acción de incumplimiento. Aunque su carga procesal fue escasa, en esta etapa surgen las primeras contribuciones del Tribunal que luego establecerían la singularidad de nuestro proceso. Por ejemplo, declaró que el ordenamiento andino: es imperativo, de aplicación obligatoria, debe se respetado por todos nosotros y regula "el proceso de la integración que se cumple en una comunidad de derecho la cual es constituida en el Pacto Andino"; ${ }^{24}$ y solo puede ser interpretado por este órgano a fin de "tutelar la vigencia del principio de legalidad en el proceso de integración andina". ${ }^{25}$

Frente a la corriente aperturista de los mercados de principios de la década de 1990 y que cambió el discurso de la CEPAL -llevándolo a apostar por el crecimiento regional en equidad y con "mercados relativamente abiertos" ${ }^{26}$, con el fin de reimpulsar y reorientar nuestro proceso subregional, en 1996 el Pacto Andino se reconfiguró como la CAN. Transformada en una organización internacional integrada por sus países miembros y el Sistema Andino de Integración (SAI), tiene entre sus objetivos la de "facilitar su participación en el proceso de integración regional, con miras a la formación gradual de un mercado común latinoamericano". ${ }^{27}$ Este rediseño organizacional también alcanzó a su órgano jurisdiccional; en ese mismo año mediante el Protocolo Modificatorio del Tratado de Creación del Tribunal de Justicia del Acuerdo de Cartagena se: consigna su actual denominación (TJCA); adiciona tres nuevas competencias como el recurso por omisión e inactividad, el arbitraje y las controversias laborales; y otorga legitimidad activa a los particulares en la acción de nulidad y en la acción de cumplimiento.

23. Ver Informe Estadístico 1984-2014 elaborado por la Secretaría General del Tribunal de Justicia de la Comunidad Andina (SGTJCA)

24. TJCA, "Sentencia del 10 de junio de 1987", Proceso 1-AN-86.

25. TJCA, "Sentencia del 3 de diciembre de 1987 (Proceso 1-IP-87)", Interpretación perjudicial de los artículos 58,62 y 64 de la Decisión 85 de la Comisión del Acuerdo de Cartagena, solicitada por el Consejo de Estado de la República de Colombia. 3 de diciembre de 1987.

26. José Antonio Sanahuja, "Regionalismo e integración en América Latina: balance y perspectivas", Revista Pensamiento Iberoamericano, . $^{\circ} 0$ (2007): 78.

27. Comunidad Andina, Acuerdo de Cartagena, 26 de mayo de 1969, Art. 1. 


\section{Desde la renovación con el Tribunal de Justicia de la Comunidad Andina hasta la actualidad}

Cumplida la revisión del ordenamiento andino para insertar a la CAN al mercado internacional y mejorar los resultados del proceso andino, sus países miembros retomaron el interés por respetar las exigencias del Acuerdo y las disposiciones del Tratado de Creación del Tribunal de Justicia de la Comunidad Andina (TJCA). Prueba de ello fue la ratificación de las modificatorias de $1996,{ }^{28}$ lo que reafirmó el compromiso de no acudir a instancias distintas al TJCA en caso de controversias sobre la interpretación y aplicación del ordenamiento andino.

En cuanto a los aspectos económicos y comerciales de la CAN, la coyuntura internacional de apertura de mercados facilitó el establecimiento de la zona de libre comercio andina; hacia 2005, cinco países miembros se beneficiaron del comercio intracomunitario. Sin embargo, el auge de una nueva ideología socialista en América del Sur -conocida como Socialismo del siglo XXI-29 ${ }^{29}$ afectó la esfera institucional del proceso andino, provocando una nueva crisis tras la salida de Venezuela de la CAN en 2006. ${ }^{30}$ Nuevamente, la falta de voluntad política de los países miembros causó que el Acuerdo fuese tildado de obsoleto, y la paralización del proceso.

A pesar de estas dificultades, el TJCA continuó enfocado en sus labores; durante la segunda y la tercera década de su funcionamiento (19952014) se recibieron: 2508 solicitudes de interpretación prejudicial, 51 acciones de nulidad, 69 acciones de incumplimientos, 6 recursos de omisión, y 18 demandas laborales. ${ }^{31}$ Este considerable incremento de la actividad jurisdiccional continuó favoreciendo el desarrollo de la singularidad del proceso andino. Respecto al ordenamiento andino, en esta etapa el TJCA

28. Comunidad Andina, Protocolo Modificatorio del Tratado de Creación del Tribunal de Justicia del Acuerdo de Cartagena, 28 de mayo de 1996.

29. Se desató una batalla política por la predominación en la región. En consecuencia, aparecieron nuevos esquemas como la Alianza Bolivariana para los Pueblos de Nuestra América-Tratado Comercial de los Pueblos (ALBA), la Comunidad de Estados Latinoamericanos y Caribeños (CELAC), la Unión de Naciones Suramericanas (UNASUR), y la Alianza del Pacífico. De allí, que la región fuese calificada como las dos Américas Latinas. José Antonio Sanahuja, "Regionalismo e integración en América Latina: de la fractura Atlántico-Pacífico a los retos de una globalización en crisis". Revista Pensamiento Propio 21, n. ${ }^{\circ} 44,(2016): 32$ y 40.

30. Venezuela denunció el Acuerdo el 22 de abril de 2006. Llegado el 2011, conforme al plazo establecido por el Artículo 135 del Acuerdo, dejó la zona de libre comercio andina.

31. Ver Informe Estadístico 1984-2014 elaborado por la SGTJCA. 
declaró: su eficacia directa; ${ }^{32}$ la jerarquización de sus normas y el principio de atribución de competencias que junto al principio de legalidad son "los dos ejes de coordenadas de la CAN"; ${ }^{33}$ y de existir controversia acerca de su aplicación e interpretación el TJCA es el único competente en resolverla. ${ }^{34}$ En relación a la consolidación del proceso andino, consideró a "la libertad esencial de circulación de mercancías como parámetro de primer orden para el avance de la integración a nivel andino y latinoamericano". ${ }^{35}$

Por lo expuesto hasta aquí, consideramos que el TJCA es el único órgano del SAI que consigue eficientes resultados para el fortalecimiento del proceso andino. Además, sus esfuerzos jurisdiccionales fueron reconocidos tras ser calificado como el tercer tribunal internacional más activo en términos del número de sentencias. ${ }^{36}$ Ciertamente existen investigaciones académicas sobre su rol en el proceso andino, en nuestra opinión el que más a cierta con la realidad de su desempeño es el realizado por Karen J. Alter, Laurence R. Helfer y M. Florencia Guerzovich. Ellos afirman que la efectividad del TJCA existe únicamente en el sector de la propiedad intelectual porque mediante su jurisprudencia se ha formado un estado de derecho que lo protege. ${ }^{37}$ En vista de ello, también se habría alcanzado una cierta armonización de las legislaciones nacionales de propiedad intelectual.

Replicar dicha línea de efectividad del TJCA para el resto de áreas del proceso andino es una tarea difícil de cumplir, ya que no solo depende de la actuación de los magistrados comunitarios. En la actualidad, la agenda política de los países miembros está más direccionada a continuar con sus

32. TJCA, "Sentencia del 24 de marzo de 1997, (Proceso 03-AI-96)", Acción de Incumplimiento interpuesta por la Junta del Acuerdo de Cartagena contra la República de Venezuela, 24 de marzo de 1997.

33. TJCA, "Sentencia del 26 de febrero de 1998 (Recaída en el Proceso 01-AN-97)", Acción de Nulidad interpuesta por la República de Venezuela contra las Resoluciones 397, 398 y 438 así como contra el Dictamen de Incumplimiento $N^{\circ}$ 11-96, expedidos por la Junta del Acuerdo de Cartagena, 26 de febrero de 1998.

34. TJCA, "Sentencia del 24 de septiembre de 1998 (Proceso 2-AI-97)", Acción de Incumplimiento interpuesta por la Secretaría General de la Comunidad Andina contra la República del Ecuador, por aplicar unilateralmente medidas restrictivas a los licores originarios y procedentes de la República de Colombia, incumpliendo expresamente los artículos 47, 71, 76 y 155 del Acuerdo de Cartagena y los artículos 5 y 33 del Tratado de Creación del Tribunal, así como la Resolución 454 de la Junta del Acuerdo de Cartagena, 24 de septiembre de 1998.

35. TJCA, "Sentencia del 10 de noviembre de 2000 (Proceso 1-AI-97)", Acción de Incumplimiento interpuesta por la Junta del Acuerdo de Cartagena contra la República de Venezuela, 10 de noviembre de 2000.

36. Alter y Helfer, Transplanting International Courts, 262.

37. Alter, Helfer y Guerzovich, "Islands of Effective International Adjudication: Constructing an Intellectual Property Rule of Law in the Andean Community", en Transplanting International Courts - The Law and Politics of the Andean Tribunal of Justice, ed. Karen J. Alter y Laurence R. Helfer (Oxford, UK: Oxford Press), 142-44. 
acuerdos de libre comercio, mantener sus membresías o formar sus propios sistemas regionales ${ }^{38}$ donde puedan lograr sus aspiraciones políticas, económicas, comerciales, y sociales. Bajo estas circunstancias, llegar a un consenso para regularizar y armonizar todos los sectores es un trayecto que carece de prioridad.

\section{Sobre las diferencias entre el Tribunal de Justicia de la Comunidad Andina y el Tribunal de Justicia de la Unión Europea}

Existe una amplia y constante discusión académica sobre el sistema institucional y jurídico de la UE y cómo su vasta experiencia la perfila a ser estándar a seguir por otros procesos o cooperaciones regionales. Gracias a su sistema jurisdiccional que garantiza y perfecciona la evolución del proceso europeo, la UE es distinta del resto de organizaciones internacionales. Por ello, si se buscara la supranacionalidad en un proceso de integración además de evaluar su instrumento fundacional, también se debe analizar cómo solucionan sus controversias. Es la naturaleza de los sistemas jurisdiccionales la que define la supranacionalidad; de existir, se observaría que ellos brindan la seguridad y legitimidad jurídica a las actuaciones de sus organizaciones mediante la aplicación efectiva de sus ordenamientos jurídicos. ${ }^{39}$

Centrándonos en nuestra investigación sobre cómo la labor del TJCA también otorga singularidad al proceso andino, en este punto lo compararemos con el TJUE. Aunque ambos tribunales son permanentes, obligatorios y exclusivos en la interpretación y la aplicación de los ordenamientos jurídicos que rigen sus respectivos procesos de integración, a simple vista no debería tildárseles de idénticos. Para encontrar las diferencias más determinantes entre ambos tribunales, revisaremos los siguientes instrumentos internacionales: el Acuerdo, el TTJCA, ${ }^{40}$ el Tratado de la UE (TUE), y el Tratado de Funcionamiento de la UE (TFUE). En base a lo último, solo

38. Por un lado, Bolivia decidió adherirse al Mercosur, y por el otro Perú y Colombia fundaron la Alianza del Pacífico. Sin embargo, todos pertenecen a la ALADI y la Comunidad de Estados Latinoamericanos y Caribeños (CELAC).

39. Levi, "La Unión Europea y la Comunidad Andina", 116-8.

40. Comisión de la Comunidad Andina, Decisión 472 sobre la codificación del Tratado de Creación del Tribunal de Justicia de la Comunidad Andina, 17 de septiembre de 1999. 
analizaremos la acción de nulidad, la acción de incumplimiento, el recurso de omisión, y la interpretación prejudicial del TJCA ya que -al parecerestas cuatro competencias también serían del TJUE.

\section{En la acción de nulidad}

Además de otorgar un amplio margen para que los particulares puedan interponer esta acción, por ejemplo solicitar la nulidad de los Convenios de Complementación Industrial, ${ }^{41}$ el TTJCA brinda un plazo de 2 años desde la entrada en vigor para impugnar-Artículo 20- las Decisiones, las Resoluciones y tales Convenios que violen el ordenamiento andino -Artículo 17-. En caso que el TJCA declare la nulidad parcial o total de la norma comunitaria o Convenio impugnado, su sentencia describirá los efectos de la nulidad en el tiempo -Artículo 22-.

Incluso vencido dicho plazo, la parte afectada que esté litigando, podrá solicitar al juez o tribunal del caso, la inaplicabilidad de la norma cuestionada -Artículo 20-. De ser admitido el pedido, el juez remitirá una consulta al TJCA sobre la legalidad de tal norma -una interpretación prejudicial-y detendrá el proceso hasta recibir respuesta, la misma que aplicará en su resolución -Artículo 20-. Por otro lado, aunque se presente la demanda de nulidad, esta no afectará la eficacia o vigencia de la norma o Convenio impugnados -Artículo 22-.

Respecto del TJUE, en vista que el TUE señala que esta institución garantiza el respeto del Derecho en la interpretación y aplicación de los Tratados -Artículo 19-, el TFUE menciona su competencia para: controlar la legalidad de tanto los actos legislativos como de los actos de ciertas instituciones, órganos u organismos de la UE que no sean recomendaciones o dictámenes; y pronunciarse sobre los "recursos por incompetencia, vicios sustanciales de forma, violación de los Tratados o de cualquier norma jurídica relativa a su ejecución, o desviación de poder". ${ }^{42}$ El plazo para interponer el recurso de nulidad es de 2 meses contados desde la publicación del acto, la notificación al afectado o desde que este haya tomado conocimiento del mismo.

41. Conforme al Derecho de los Tratados, sólo los Estados pueden solicitar la nulidad de los instrumentos internacionales.

42. Comunidad Andina, Tratado de Funcionamiento de la Unión Europea, 13 de diciembre de 2007, Art. 263. 
Si bien el TFUE reconoce la legitimidad activa a ciertas instituciones y órganos, también la otorga a los particulares (siempre que prueben que los actos que sea destinataria y los actos reglamentarios que no incluyan medidas de ejecución les afecten directa e individualmente -Artículo 263-). Distinta condición presenta el TJCA al indicar que los particulares pueden impugnar la norma o Convenio que afecta sus derechos subjetivos o intereses legítimos-Artículo 19-.

\section{En la acción de incumplimiento}

Para la legislación europea, el TFUE señala que esta acción procede cuando un Estado miembro haya incumplido alguna obligación de los Tratados -Artículo 259-, teniendo legitimidad activa ${ }^{43}$ para iniciarla en fase pre contenciosa o administrativa los Estados y la Comisión Europea -Artículo 258-. Esta última actúa de oficio o por denuncia directa de algún Estado; en caso no expida un dictamen motivado en tres meses contados desde el ingreso del reclamo -Artículo 259-, el o los Estados solicitantes podrán iniciar la fase contenciosa en el TJUE.

Caso distinto presenta el TTJCA al permitir que los particulares puedan iniciar ambas fases, siempre y cuando prueben qué derechos les han sido afectados -Artículo 25-. Además, el TTJCA establece los siguientes plazos: no mayor a 60 días para que el país miembro requerido presente sus descargos a la Secretaría General (SGCAN) y para la investigación que realizará la SGCAN (si la fase administrativa fue solicitada por un país miembro); la emisión del dictamen motivado de la SGCAN: dentro de los 15 días siguientes al anterior plazo; el inicio de la fase judicial por el país miembro afectado: después de 60 días contados desde la emisión del dictamen de incumplimiento y si el país requerido persiste en su conducta, siempre y cuando la SGCAN no haya presentado demanda al TJCA; y, después de 65 días desde la presentación del reclamo en la SGCAN y si esta no emitió dictamen alguno.

Sobre la sentencia de incumplimiento, el TFUE menciona que si el Estado afectado no adopta medidas necesarias para su ejecución, y tampoco realiza sus descargos sobre su conducta a la Comisión Europea, esta

43. La Comisión Europea también toma conocimiento de los incumplimientos estatales por las quejas de los particulares que estén sustentadas. 
propondrá el pago de una suma a tanto alzado o de la aplicación de una multa coercitiva al TJUE. Si este verifica tal incumplimiento, dispondrá dicho pago o multa -Artículo 260.2-. En cambio, el Artículo 27 TTJCA especifica el plazo para que el país miembro infractor adopte las medidas necesarias dispuestas por el TJCA en su sentencia: (no mayor a 90 días, contados desde su notificación). Si las incumpliera, el TTJCA señala una sanción distinta que el TJCA impondrá previa opinión de la SGCAN, la misma que está referida a los límites bajo las cuales cualquier país miembro podrá restringir o suspender, total o parcialmente, las ventajas del Acuerdo que beneficien al país miembro infractor.

\section{En el recurso de omisión}

En el ámbito europeo, el TFUE dice que: los plazos para requerir a la institución, órgano u organismo omiso el cumplimiento, y la postulación del proceso son dos meses; y los particulares solo pueden recurrir en queja al TJUE, cuanto tales instituciones, órganos u organismos no les han dirigido un acto distinto a la recomendación o dictamen -Artículo 265-. Distinto tratamiento contiene el TTJCA al delimitar a 30 días la interposición del recurso y dictar sentencia detallada para su cumplimiento -Artículo 37-.

\section{En la interpretación o cuestión prejudicial}

Como proceso no contencioso, el TTJCA consigna que solo los jueces nacionales la remiten -Artículo 33- al TJCA para que interprete el ordenamiento andino. Sin embargo, este entiende que también cumple dicha obligación cualquier funcionario administrativo con función jurisdiccional y el árbitro en derecho. ${ }^{44}$ Respecto a su labor interpretativa, el TJCA la realiza para cada caso concreto ocasionando repetitivas interpretaciones. En cambio, el TJUE aplica la doctrina del acto aclarado, ${ }^{45}$ y en base a los dispuesto en que el TFUE admite los pedidos de los órganos jurisdiccionales para interpretar los Tratados como validar e interpretar los actos adop-

44. TJCA. "Sentencia del 26 de agosto de 2011. (Proceso 03-AI-2010)", Acción de Incumplimiento interpuesta por la Empresa de Telecomunicaciones de Bogotá S.A. ESP, (ETB S.A. E.S.P.) contra la República de Colombia, 26 de agosto de 2011.

45. María Angela Sasaki Otani, "El sistema de sanciones por incumplimiento en el ámbito de la Comunidad Andina", Anuario Mexicano de Derecho Internacional XII, (2012): 310-1. 
tados por las instituciones, órganos u organismos de la UE -Artículo 267-. Además, para el TJUE califican como órganos jurisdiccionales si se cumple con los siguientes criterios: ${ }^{46}$ el origen legal del órgano, su permanencia, el carácter obligatorio de su jurisdicción, el carácter contradictorio del procedimiento, la aplicación por parte del órgano de normas jurídicas y su independencia. Por tanto, no todos los órganos administrativos ni tribunales arbitrales de los Estados miembros estarían integrados en el sistema jurisdiccional de la UE.

\section{El Tribunal de Justicia de la Comunidad Andina y la singularidad del proceso de integración andino}

Si bien la CAN no ha aplicado todos los mecanismos y medidas para cumplir con sus objetivos $-{ }^{47}$ no existe arancel externo común y tampoco liberalización del comercio de servicios-, consideramos que la labor del TJCA resulta importante en el reconocimiento de la supranacionalidad del proceso andino. A nivel mundial, existen dos tribunales responsables de la tutela jurisdiccional de ordenamientos comunitarios, el nuestro es el segundo. En consecuencia, no existen otros procesos similares en esta región, muy a pesar de las opiniones ${ }^{48}$ que califican al Mercado Común del Sur (Mercosur) y al Sistema de Integración Centroamericano (SICA) como supranacionales.

Plantear una negociación sobre el próximo estadío del proceso andino resultaría irrelevante para los países miembros: oficialmente se decidió eli-

46. Ver las sentencias del TJUE de los Asuntos 61/65, 102/81, 14/86, 318/85, C-192/98, C-100/89, C-101/89, C-337/95, C-555/13, y 284/16.

47. Artículo 3 del Acuerdo.

48. Carmina Crusafon señala como "dos entidades supranacionales" al Mercosur y a la UE. Ver "La política audiovisual del MERCOSUR y la influencia del modelo europeo", Cuadernos de Información 25, (2009): 94 y 101; Jorge Fernández Reyes reconoce que "algunos autores trata de fundamentar la existencia de un Derecho Comunitario... en el MERCOSUR, llegando en ocasiones a afirmar la existencia de un derecho supranacional". Ver "La aplicación del derecho en el MERCOSUR, Revista de la Secretaría del Tribunal Permanente de Revisión, 14, (2019): 17; Víctor Miguel Vega Brizuela afirma que: "La creación del SICA, representó para la región el establecimiento de un nuevo ordenamiento jurídico supranacional, regido por el derecho comunitario Centroamericano; [...]". Ver "El fortalecimiento institucional del SICA a través de la adopción del Reglamento de Organización y Funcionamiento del Consejo de Ministros de Relaciones Exteriores", Revista Centroamericana de Administración Pública, n. ${ }^{\circ} 74$; Ver Comisión de la Comunidad Andina, Decisión 563 sobre la codificación del Acuerdo de Integración Subregional Andino (Acuerdo de Cartagena), 25 de junio de 2003. 74 (2018): 59. 
minar la búsqueda del arancel externo común. ${ }^{49}$ Ahora ellos apuestan por otras relaciones interestatales que les permitan mejorar sus políticas públicas y elevar sus marcadores macroeconómicos en el corto plazo. Creemos que la persistente desigualdad en el desarrollo de estos países es una de las tantas causas que impide la total eficacia del ordenamiento andino. Con este panorama, es casi impensable que el TJCA reciba la valoración y el respeto que merece.

A pesar que aún los operadores administrativos y judiciales son rea$\operatorname{cios}^{50}$ a cumplir con el ordenamiento andino -por ejemplo, solicitar interpretaciones prejudiciales-, esto no significa que en los últimos años se haya generalizado el desinterés por el TJCA. Así tenemos que en el periodo 2015-2019 su actividad jurisdiccional aumentó significativamente tras recibir: 3140 solicitudes interpretaciones prejudiciales, 21 acciones de nulidad, 21 acciones de incumplimientos, 4 recursos de omisión, 5 demandas laborales, y 2 solicitudes de arbitraje. ${ }^{51}$ Durante estos años, las aportaciones más resaltantes del TJCA que sustentan la singularidad del proceso andino son las siguientes: los particulares "no pueden interponer la acción de incumplimiento como un recurso contra las actuaciones del juez nacional"; 52 la afectación al derecho subjetivo o interés legítimo "debe ser concreta, real y directa, la respuesta debe ser oportuna;" ${ }^{3}$ y es competente "para realizar una revisión profunda de los requisitos de validez de los actos administrativos emitidos por la Secretaría General de la CAN". ${ }^{44}$

No creemos que el proceso andino sea una copia ${ }^{55}$ íntegra del proceso europeo por las siguientes razones: cuatro de las seis competencias del TJCA son parcialmente distintas a las del TJUE; el TJCA no sigue la

49. Comisión de la Comunidad Andina, Decisión 805 sobre la política arancelaria de la Comunidad Andina, 24 de abril de 2015.

50. Phelan, "Enforcement and Escape in the Andean Community", 845.

51. Ver los Informes Anuales de Gestión del TJCA años 2015, 2016, 2017, 2018 y 2019.

52. TJCA,"Sentencia del 7 de julio de 2017. (Proceso 01-AI-2015)". Acción de incumplimiento ejercida por Ángela Vélez Escallón en contra de la República de Colombia por el supuesto incumplimiento de los artículos 4,33,35 y 36 del Tratado de Creación del Tribunal de Justicia de la Comunidad Andina, 7 de julio de 2017.

53. TJCA, "Sentencia del 3 de octubre de 2017. (Proceso 03-AI-2017)", Acción de Incumplimiento interpuesta por Flores Maravilla S.A contra la República de Colombia, 3 de octubre de 2017.

54. TJCA, "Sentencia del 19 de enero de 2017 (Recaída en el Proceso 01-AN-2014 )", Acción de Nulidad interpuesta por la República del Ecuador contra las Resoluciones 1695 y 1716 emitidas por la Secretaría General de la Comunidad Andina, 19 de enero de 2017.

55. Alter y Helfer, "The Andean Tribunal of Justice and its interlocutors: Understanding preliminary reference patterns in the Andean Community", 874. 
misma jurisprudencia y doctrina del TJUE ${ }^{56}$ para sentenciar; el Artículo 27 TTJCA; y la función arbitral y la jurisdicción laboral no son competencias del TJUE. ${ }^{57}$

Al igual que William Phelan, consideramos que dicha norma comunitaria, junto a la labor del TJCA, terminan por distanciar el proceso andino del europeo, configurándose como singular o único entre los procesos de integración supranacional. Phelan afirma que si bien en la UE hay un reiterado rechazo a las contramedidas interestatales -en su modalidad de represalias comerciales-, de existir estarían reguladas por el Derecho Internacional ${ }^{18}$ y no por el Derecho Comunitario. En consecuencia, la sanción que recoge el Artículo 27 TTJCA sobre la restricción de las ventajas económicas y comerciales del Acuerdo estaría regida por el ordenamiento internaciona ${ }^{59}$ y no por el andino. Finalmente, todo esto nos conduce a sostener que nuestra apreciación de la singularidad del proceso andino es sólida y real, precisamente porque este proceso se adapta a las realidades de los países miembros de la CAN, lo que también permite la generación de una identidad andina.

\section{Conclusiones}

Terminado con la exposición de los fundamentos que demuestran la singularidad del proceso andino, llegamos a las siguientes conclusiones:

La configuración y el mecanismo de la CAN no son copia fiel de la UE, ya que en su momento este solo sirvió de inspiración y modelo a seguir. La razón de ello se encuentra, tanto en el trabajo del TJCA como el ordenamiento andino -en especial el Artículo 27-, y que en conjunto permiten que el proceso andino adquiera una naturaleza singular.

56. Saldías, "Networks, Courts and Regional Integration Explaining the Establishment of the Andean Court of Justice", 18.

57. La función principal del TJUE es garantizar el respeto del ordenamiento europeo tanto en su interpretación como aplicación, y no la de resolver controversias de particulares y tampoco la de dirimir sobre asuntos laborales entre los funcionarios o empleados y las instituciones, órganos u organismos de la UE.

58. Phelan, "Enforcement and Escape in the Andean Community", 849.

59. María Angela Sasaki Otani opina que "la Comunidad Andina aún cuenta con un mecanismo de sanciones con visos de "intergubernamentalidad" [...] porque quien decide aplicar o no la sanción "autorizada" son [...] solo los países miembros (y no el TJCA)". Ver "El sistema de sanciones por incumplimiento en el ámbito de la Comunidad Andina”, 311. 
Bajo esa perspectiva, el ordenamiento andino también se convierte en único o singular en cuanto a la regulación de procesos de integración supranacionales. De allí, que se entienda la gran importancia de la actividad jurisdiccional de la TJCA en el proceso andino para que siga perfeccionando desde su ámbito singular y no uno idéntico por restarle parte de su identidad andina.

\section{Bibliografía}

Alter, Karen J. y Helfer, Laurence R. "The Andean Tribunal of Justice and its interlocutors: Understanding preliminary reference patterns in the Andean Community". Journal of International Law and Politics 41, n. ${ }^{\circ} 4$ (2009): 871-929.

- Transplanting International Courts. The Law and Politics of the Andean Tribunal of Justice. Oxford: Oxford University Express, 2017.

Alter, Karen, Helfer, Laurence R y Guerzovich, M. Florencia. "Islands of Effective International Adjudication: A Constructing an Intellectual Property Rule of Law in the Andean Community". En Transplanting International Courts - The Law and Politics of the Andean Tribunal of Justice, editado por Karen J. Alter y Laurence R. Helfer, 111-71. Oxford, UK: Oxford University Express, 2017.

Comisión de la Comunidad Andina. Decisión 472 sobre la codificación del Tratado de Creación del Tribunal de Justicia de la Comunidad Andina. 17 de septiembre de 1999. ‘https://bit.ly/2CCOiKL〉.

—. Decisión 563 sobre la codificación del Acuerdo de Integración Subregional Andino (Acuerdo de Cartagena). 25 de junio de 2003. https://bit.ly/3g9SCNs».

Decisión 805 sobre la política arancelaria de la Comunidad Andina. 24 de abril de 2015. https://bit.ly/3158gFE〉.

Comunidad Andina, Acuerdo de Integración Subregional. 26 de mayo de 1969. https:// bit.ly/34bpOSE.

- Tratado de Creación del Tribunal de Justicia del Acuerdo de Cartagena, 28 de mayo de 1979.

- Acta de Caracas - V Reunión del Consejo Presidencial Andino. 17 y 18 de mayo de 1991.

- Protocolo Modificatorio del Tratado de Creación del Tribunal de Justicia del Acuerdo de Cartagena, 28 de mayo de 1996. 〈https://bit.ly/3h7ghQc〉.

Crusafon, Carmina. "La política audiovisual del MERCOSUR y la influencia del modelo europeo". Cuadernos de Información 25, (2009): 93-104. https://bit. ly/33gSYza>.

Fernández Reyes, Jorge. "La aplicación del derecho en el MERCOSUR". Revista de la Secretaría del Tribunal Permanente de Revisión 7, n. 14 (2019): 14-43. doi: 10.16890/rstpr.a7.n14.p14 
Instituto para la Integración de América Latina y El Caribe. Estudio sobre Procedimientos para Solucionar Conflictos, 1972.

Levi, Michel. "La Unión Europea y la Comunidad Andina: relaciones entre los procesos de integración”. En Europa y América Latina. El otro diálogo transatlántico, editado por José María Beneyto y Patricia Argerey, 113-36. Madrid, ES: Instituto Universitario de Estudios Europeos, 2006.

Lochridge, Edwin P. "The Role of the Andean Court in Consolidating Regional Integration Efforts". Georgia Journal of International and Comparative Law 10, n. ${ }^{\circ}$ 2 (1980): 351-83.

Orrego Vicuña, Francisco. "La creación de un tribunal de justicia en el Grupo Andino", Revista Derecho de la Integración 15, (1974): 31-45.

Prebisch, Raúl. "El desarrollo económico de la América Latina y algunos de sus principales problemas". En Cincuenta años del pensamiento de la CEPAL: textos seleccionados, editado por Naciones Unidas CEPAL, 63-126. Santiago, CH: Fondo de Cultura Económica, 1998.

Phelan, William. "Enforcement and Escape in the Andean Community: Why the Andean Community of Nations is Not a Replica of the European Union". Journal of Common Market Studies 53, n. ${ }^{\circ} 4$ (2015): 840-56. doi: 10.1111/jcms.12222

Quindimil, Jorge Antonio. Instituciones y Derecho de la Comunidad. Valencia: Tirant lo Blanch, 2006.

Sáchica, Luis Carlos. "El Ordenamiento Jurídico Andino y su Tribunal de Justicia". En El Tribunal de Justicia del Acuerdo de Cartagena, editado por Instituto para la Integración de América Latina, 5-26. Buenos Aires, ARG: INTAL, 1985.

Saldías, Osvaldo. "Networks, Courts and Regional Integration Explaining the Establishment of the Andean Court of Justice". KFG Working Paper Series, n. 20 (2010): 1-27. 〈https://bit.ly/3k4MpWz〉.

Sanahuja, José Antonio. "Regionalismo e integración en América Latina: balance y perspectivas". Revista Pensamiento Iberoamericano, n. ${ }^{\circ}$ (2007): 75-106. https://bit.ly/39RDkM6>.

. "Regionalismo e integración en América Latina: de la fractura Atlántico-Pacífico a los retos de una globalización en crisis". Revista Pensamiento Propio 21, n. ${ }^{\circ} 44,(2016): 29-76$. 〈https://bit.ly/3ff7auY>.

Sasaki, María Ángela. "El sistema de sanciones por incumplimiento en el ámbito de la Comunidad Andina”. Anuario Mexicano de Derecho Internacional XII, (2012): 301-37. doi: 10.22201/iij.24487872e.2012.12.400

Secretaría General del Tribunal de Justicia de la Comunidad Andina. Informe Estadístico 1984-2014, s/f.

Tribunal de Justicia de la Comunidad Andina. Informe de Labores Gestión 2015. 〈https://bit.ly/31gnc2S .

Informes de Labores Gestión 2016. «https://bit.ly/33jCHJQ>.

Informes de Labores Gestión 2017. 〈https://bit.ly/2DurgUB〉.

Informes de Labores Gestión 2018. 〈https://bit.ly/318YAZN〉. 
Informes de Labores Gestión 2019. 〈https://bit.ly/2D2Neyx〉.

"Sentencia del 10 de junio de 1987, Proceso 1-AN-86".

"Sentencia del 3 de diciembre de 1987 (Proceso 1-IP-87)". Interpretación perjudicial de los artículos 58,62 y 64 de la Decisión 85 de la Comisión del Acuerdo de Cartagena, solicitada por el Consejo de Estado de la República de Colombia. 3 de diciembre de 1987.

"Sentencia del 24 de marzo de 1997, (Proceso 03-AI-96)". Acción de Incumplimiento interpuesta por la Junta del Acuerdo de Cartagena contra la República de Venezuela. 24 de marzo de 1997.

"Sentencia del 26 de febrero de 1998 (Recaída en el Proceso 01-AN-97)". Acción de Nulidad interpuesta por la República de Venezuela contra las Resoluciones 397, 398 y 438 así como contra el Dictamen de Incumplimiento № 11-96, expedidos por la Junta del Acuerdo de Cartagena. 26 de febrero de 1998.

"Sentencia del 24 de septiembre de 1998 (Proceso 2-AI-97)". Acción de Incumplimiento interpuesta por la Secretaría General de la Comunidad Andina contra la República del Ecuador, por aplicar unilateralmente medidas restrictivas a los licores originarios y procedentes de la República de Colombia, incumpliendo expresamente los artículos 47, 71, 76 y 155 del Acuerdo de Cartagena y los artículos 5 y 33 del Tratado de Creación del Tribunal, así como la Resolución 454 de la Junta del Acuerdo de Cartagena. 24 de septiembre de 1998.

"Sentencia del 10 de noviembre de 2000 (Proceso 1-AI-97)". Acción de Iincumplimiento interpuesta por la Junta del Acuerdo de Cartagena contra la República de Venezuela. 10 de noviembre de 2000.

"Sentencia del 26 de agosto de 2011. (Proceso 03-AI-2010)". Acción de Incumplimiento interpuesta por la Empresa de Telecomunicaciones de Bogotá S.A. ESP, (ETB S.A. E.S.P.) contra la República de Colombia. 26 de agosto de 2011. "Sentencia del 7 de julio de 2017. (Proceso 01-AI-2015)". Acción de Incumplimiento ejercida por Ángela Vélez Escallón en contra de la República de Colombia por el supuesto incumplimiento de los artículos 4,33,35 y 36 del Tratado de Creación del Tribunal de Justicia de la Comunidad Andina. 7 de julio de 2017.

"Sentencia del 3 de octubre de 2017. (Proceso 03-AI-2017)". Acción de Incumplimiento interpuesta por Flores Maravilla S.A contra la República de Colombia. 3 de octubre de 2017.

"Sentencia del 19 de enero de 2017 (Proceso 01-AN-2014)". Acción de Nulidad interpuesta por la República del Ecuador contra las Resoluciones 1695 y 1716 emitidas por la Secretaría General de la Comunidad Andina. 19 de enero de 2017.

Unión Europea. "Versiones Consolidadas del Tratado de la Unión Europea y del Tratado de Funcionamiento de la Unión Europea”. Diario Oficial de la Unión Europea. 7 de junio de 2016.

Vega Brizuela, Víctor Manuel. "El fortalecimiento institucional del SICA a través de la adopción del Reglamento de Organización y Funcionamiento del Consejo de Ministros de Relaciones Exteriores". Revista Centroamericana De Administración Pública, n. ${ }^{\circ} 74$ (2018): 57-66. doi: 10.35485/rcap74_4 